\title{
VAREIROS DO RIO GRAJAÚ
}

\section{Alan Kardec Gomes Pachêco Filho alankardecpacheco@uol.com.br}

RESUMO: O presente estudo analisa a História, a memória e as condições, de trabalho dos vareiros do rio Grajaú, localizado no centro sul maranhense, no início do século XX, discutindo como aquela atividade exercida por homens negros e índios podem ser consideradas análogas à escravidão. Dialogo com os autores E.P.Thompson e Frederick Cooper e com os autores Jacy Alves de Seixas, Michael Pollak, Pierre Nora e Maurice Halbwachs sobre a questão da memória.

PALAVRAS CHAVE: Maranhão, Navegação Fluvial, Memória, Homens Livres, Escravidão.

Este artigo é resultado de uma pesquisa em desenvolvimento que faço como aluno do programa de Pós-Graduação da UFF. Dialogo com alguns autores a fim de refletir acerca do objeto em questão, ou seja, a navegação fluvial no Vale do rio Grajaú e o esquecimento por parte da sociedade grajauense dos principais agentes do desenvolvimento da região por mais de um século: $o$ Vareiro. Dentre as discussões que convergiram e contribuíram para uma reflexão sobre o tema estão: Jacy Alves de Seixas, E. P. Thompson, Frederick Cooper, Michael Pollak, Maurice Halbwachs e Pierre Nora. Esses autores tornam-se importantes no desenvolvimento teórico-metodológico desta discussão centrada no trabalho exercido pelos Vareiros do Rio Grajaú não somente pelos aspectos conceituais inseridos em seus trabalhos, mas, sobretudo, pela

\footnotetext{
* Doutorando do Programa de Pós-Graduação em História Social da Universidade Federal Fluminense. Professor do Departamento de História e Geografia da Universidade Estadual do Maranhão.
} 
lógica com que lidam com seus temas, ou seja, o que se busca desses autores não é o engessamento de seus modelos explicativos.

O articulista Sálvio Dino em sua coluna semanal no periódico, O Estado do Maranhão, publicou em 25 de junho de 2002, em artigo no qual analisava e comemorava o asfaltamento da BR 226, estrada que liga a cidade de Grajaú, localizada no centro sul maranhense, à capital São Luís, assim se expressava:

[...] Agora, o governador José Reinaldo vem de inaugurar oficialmente a tão sonhada rodovia 226 - ligando em menor espaço de tempo e com maior economia de combustível o velho Grajaú à capital do estado e ao Planalto Central. Chegou em termos de comunicação rodoviária moderna, o que tanto queríamos. Pois bem. Em tão importante data (recordo emocionado os sentidos apelos que eu fazia da tribuna da Assembléia Legislativa clamando pelo asfaltamento dessa estrada de integração, autêntica alavanca desenvolvimentista dos nossos vales verdes, povoados de gente laboriosa e riquezas precisando de boas vias de escoamento) sinto que se deve prestar justa e merecida homenagem aos heróicos pioneiros da comunicação grajauense: o inesquecível e bravo vareiro. Nunca será tarde dizer-se alto e a bom som: o desenvolvimento do Porto da Chapada (fundado em 1811), deveu-se à navegação do seu rio. Através deste pôde Grajaú transformar-se no principal empório comercial da região centro-sul do estado. Houve época em que Caxias e Grajaú no Império foram as duas maiores cidades do interior maranhense portanto, meu abraço afetuoso a todos os descendentes dos destemidos navegadores da ribeira grajauense. Que tal a idéia de levantar-se um monumento ao vareiro grajauense! Pense na idéia, minha cara prefeita Bernadete. (grifo meu). (OEMA, Caderno Alternativo, p. 6).

O articulista recomenda à prefeita a construção de um monumento, que pudesse ser o elo entre a identidade social e a memória. A memória só pode emergir de um grupo que ela une, no dizer de Halbwachs (2006), há tantas memórias quantos grupos existentes. Ela é, por natureza, múltipla, coletiva e individual. Quer o articulista a construção da memória erigida em pedra e cal como a cristalização de "um lagar da memória" como se o esquecimento "fosse uma vergonha" e não uma parte dessa mesma memória. 
Essa crescente revalorização da memória, tanto na esfera pública quanto na individual, o acúmulo de falas da memória, torna cada vez mais comum e às vezes nem tanto eficaz, manifestações como a do articulista sobre o direito e o dever da preservação da memória de minorias, cada vez mais reivindicada no seio da sociedade civil (SEIXAS, 2004, p.37). Vivemos a febre da memória.

Nesse sentido, é por meio da memória que se chega à história dos Vareiros que desciam e subiam o rio Grajaú no centro sul do Maranhão, com suas canoas cheias de mercadorias em direção ao norte, mais exatamente ao município de Vitória do Mearim, localizada na baixada maranhense, há oitocentos quilômetros de distancia de onde partiam. Os registros escritos desse périplo são ainda escassos se comparados à memória coletiva ainda existente. Daí porque o recurso da História oral torna-se fundamental na elaboração dessa história.

Sabe-se que o historiador necessita confrontar a memória com documentos. Por isso a investigação da documentação escrita é um suporte do qual não se pode abrir mão. Assim, registros relativos à navegação fluvial no rio Grajaú, jornais, correspondências comerciais, notas fiscais e cartas, além das referências de estudiosos da história econômica do Maranhão, possibilitarão uma análise da conjuntura à qual estiveram inseridos esses sujeitos históricos.

A utilização da História oral é essencial para se discutir as formas de trabalho escravo em relação às condições de trabalho dos Vareiros do Rio Grajaú no início do século XX. O fascínio do vivido (ALBERTI, 2004, p.14) é responsável pelo sucesso que a História oral tem alcançado não só no Brasil. As entrevistas revelam pedaços do passado, experiências de vidas. As narrativas dos sujeitos dão cor à vida e tornam singular essa experiência humana.

O estudo do centro sul maranhense desde os tempos coloniais foi relegado a segundo plano. Há trabalhos sobre essa região publicados no século XIX e XX como os de (RIBEIRO, 1848), (ALMEIDA, 1852), (CARVALHO, 1924), dedicados ao estudo descritivo do sertão maranhense. A referência mais recente e hoje obrigatória é a historiadora Maria do Socorro Coelho Cabral (1992). Entretanto a autora não se ocupou da navegação fluvial nem do mercado regional de gêneros secos e molhados feitos na hinterlândia de Grajaú em razão de seu objeto ser a colonização do sul maranhense. 
O rio Grajaú foi responsável pela integração de dois espaços distintos: o centro sul e o norte maranhense. Foi cenário de histórias de duas sociedades diferenciadas: a sertaneja, distanciada do controle político dos líderes da Capital, marcada pela criação do gado vacum e muar, pela presença de vaqueiros e por homens de "espírito patriótico e livre", e a litorânea, identificada pelo predomínio da agricultura, agro exportação, escravidão e influência dos costumes europeus.

O rio Grajaú, um dos principais afluentes do rio Mearim, uniu essas duas fronteiras históricas. Tinha como principais agentes da integração os Vareiros, cujo trabalho consistia em empurrar canoas com longas e pesadas varas apoiadas no peito. Esse trabalho, desumano para alguns, tinha sua mão-de-obra fornecida por índios, negros e brancos pobres, recrutados na periferia do município de Grajaú e nas aldeias próximas, especialmente a aldeia do Morro Branco, hoje um bairro da referida cidade.

As canoas eram construídas em estaleiros rudimentares, localizados nas margens do rio Grajaú. Um dos principais "estaleiros" estava no povoado Jaburu, localizado há pouco mais de vinte quilometro da sede do município. Eram geralmente oficinas compostas aproximadamente por vinte e cinco trabalhadores membros de um mesmo núcleo familiar entre pais, filhos, cunhados, compadres e sobrinhos. Para os operários dessa "indústria", o tempo é o tempo de fabricação da canoa, da mesma forma que observou Pritchard apud (THOMPSON, 2005, p.269) ao analisar o tempo de uma comunidade africana - os nuer: “o relógio diário é o do gado, a rotina das tarefas pastorais, e para um nuer as horas do dia e a passagem do tempo são basicamente a sucessão dessas tarefas e a sua relação mútua".

A tarefa de construção das canoas tinha início por volta do mês de julho de cada ano quando os comerciantes de Grajaú faziam suas encomendas. Feito o compromisso do contrato da fabricação da canoa, normalmente assegurado pelo valor dado à "palavra" e à "honra", o proprietário do "estaleiro" começava a escolher e a convocar os trabalhadores, que quase sempre eram os mesmos. Nos próximos sete meses, todos trabalhariam num ritmo que obedecia ao "cantar do galo", para despertarem e iniciarem as atividades diárias, e pelo pôr-do-sol, para encerrá-las. Entretanto, os preparativos para a fabricação de uma canoa começavam muito antes.

O "nascimento de uma canoa" era resultado de um longo processo em que a relação do trabalho com o tempo, com as experiências de vida e com as condições de 
trabalho desses indivíduos era marcada pela situação extremada de degradação da condição humana. Esse ambiente muito próximo do regime de escravidão vivido pela intensa jornada de trabalho, pela presença de crianças ou pelo tipo de alimentação foi descrito com detalhes em depoimento prestado por (ARRUDA, 2007), um dos trabalhadores que vivenciou essa experiência:

\begin{abstract}
Um barco nasce na mata. Meu pai saía era uma hora da manhã com uma foice, um facão e uma cabaça d'água abrindo picada e 'escoiendo' pau. Quando ele achava os paus 'tudim', marcava os pé dele, limpava bem 'limpim' e voltava. Tinha dia que ele só chegava de noite. Depois eu, já com idade de oito pra nove anos, ia tocando três junta de boi, durante um mês mais ou menos era esse o meu serviço. Quando chegava ia pilar arroz pra fazer comida pros 'trabaiador', botar os boi pra pastar na quinta e ia dormir. Pouco tempo depois eu levantava e ia buscar água no rio com as cabaças mode encher os pote. Teve um dia que me acordei dormindo dentro do rio, não sei como não morri. 'Sô', era uma escravidão!
\end{abstract}

Como se não bastassem as dificuldades para encontrar a madeira ideal para a construção da canoa, o transporte até a oficina constituía-se em outro grande desafio: juntas de bois conduzidas por crianças tinham que adentrar à mata cada vez mais para o interior à medida que a madeira tornava-se escassa e arrastá-la até o local do fabrico da canoa a pouco mais de cinqüenta metros do rio. Nessa tarefa, como em muitas outras decorrentes da construção do barco, a presença de crianças, conforme o relato, era constante e indispensável. Nessas condições de trabalho, vivia-se em condições análogas à escravidão.

A "indústria" da construção de canoas envolvia carpinteiros, calafates, serradores de toras de madeira, ferreiros, dentre outros, em diferentes jornadas de trabalho para não interromper o ritmo da produção. Os carpinteiros, os calafates, e os serradores cumpriam sua jornada durante o dia enquanto os ferreiros trabalhavam na produção de pregos geralmente à noite (SILVA, 2007) " "esticando, cortando e soldando ferro para fazer prego. Não podia faltar prego durante a jornada diária". Mestres davam forma e "vida" às canoas que depois subiriam e desceriam o rio Grajaú empurradas a varas pelas mãos hábeis e peitos calejados dos Vareiros.

A partir das reflexões propostas por Thompson pode-se compreender que “esse ambiente vivido que incluía práticas, expectativas herdadas, regras que não só

\footnotetext{
${ }^{1}$ Depoimento prestado ao Autor por Edvalso Silva, 67 anos, na cidade de Grajaú - MA, em 19/01/2007.
} 
impunham limites aos usos como revelam possibilidades, normas e sanções. (Thompson, 2006, p. 90). Tais regras e normas eram percebidas na fidelidade que 0 grupo de trabalhadores devia ao chefe familiar e também no cotidiano, pois, durante o período de construção da canoa, os hábitos eram quase sempre os mesmos dos anos anteriores, de construções anteriores. O que alterava, às vezes, era a inclusão ou exclusão de um ou outro trabalhador.

A presença de uma memória coletiva entre os ribeirinhos acerca dos acontecimentos "vividos pelo grupo ou pela coletividade à qual a pessoa se sente pertencer" (POLLAK, 1992, p.2), ou seja, o lócus de fragmentos de experiências de vidas desses trabalhadores, não está somente entre os que estiveram diretamente envolvidos nos ofícios relacionados às atividades da navegação. Durante as entrevistas, as conversas surgidas entre os familiares, cujo teor tratava da fabricação de canoas, do trabalho em roças, das dificuldades materiais vividas do período de construção, do pagamento dos operários, eram temas recorrentes na memória dos familiares.

Sobre as formas de pagamento dos operários da construção de canoas, $(\text { ARRUDA, 2007) })^{2}$ diz:

\begin{abstract}
O senhor que encomendava o barco só adiantava produtos. Era mescla, riscado, morim, brim branco, seda lamê, naquele tempo tinha uma seda lamê, chita, riscado, edite, gabardina, cáqui Floriano, aquele amarelão mesmo, ainda usei muito. Rapadura, querosene, sal, açúcar, café, pólvora, chumbo, espingarda por fora. Era como adiantamento, esse o meu pai arrumava pros trabaiador. O meu pai não tinha nada não, meu pai foi um velho muito sério, não gostava de trambique, não marretava ninguém, o que ele fazia ele dizia, olha rapaz, fiz isso. Cansei de vim aqui (Grajaú) pegar dinheiro. Nóis passava três quatro dia para ele arrumar o dinheiro.
\end{abstract}

No ensaio condição análoga à escravidão, Cooper faz referência ao fato de a escravidão ter sido abolida. Contudo, mesmo que oficialmente o sistema tenha sido extinto, houve uma clara permanência de formas de trabalho e uma prática de remuneração que, em muitos casos, assemelhava-se às condições de vidas sob as quais os trabalhadores escravos estavam submetidos. Nessa perspectiva, os trabalhadores da "indústria naval" e os Vareiros do rio Grajaú sofriam pressões muito parecidas daquelas feitas sobre os trabalhadores escravos. A forma de pagamento em

\footnotetext{
${ }^{2}$ Depoimento prestado ao Autor, por Luiz Alves de Arruda, 74 anos, na cidade de Grajaú - MA em 03/08/2007.
} 
produtos reafirma a tese aqui proposta das condições análogas daqueles trabalhadores à escravidão. Pagar em produtos era uma forma de manter o cativeiro.

A NAVEGAÇÃO FLUVIAL NO VALE DO RIO GRAJAÚ: AS RELAÇÕES DE TRABALHO ESCRAVO ENTRE HOMENS LIVRES E POBRES NO INÍCIO DO SÉCULO XX NO MARANHÃO

Os Vareiros foram homens pobres e, em sua maioria, eram homens negros e índios que dedicaram anos de suas vidas a um trabalho árduo na lida diária do transporte fluvial. Ao enfrentarem situações tão difíceis, muitos pagaram com a própria vida o preço das adversidades de tal trabalho. O cotidiano desses trabalhadores tinha início muito cedo. O cozinheiro do dia (era feito um rodízio de modo que todos cozinhassem) levantava-se por volta das três horas da manhã para fazer o almoço. Os demais se levantavam por volta das cinco da manhã. Às sete todos eram convidados para a primeira refeição diária: o almoço. Depois de comerem quase invariavelmente o mesmo cardápio do dia anterior, arroz, fava com toucinho, carne e uma boa quantidade de farinha, que a água do rio Grajaú ajudava a engolir, iniciavam o trabalho.

Vestidos com seus toscos trapos que geralmente Ihes cobriam apenas a virilha, começavam a andar lentamente, um após outro, passo a passo, da popa para a proa da canoa. Eles caminhavam para trás dando a idéia de que voltavam para o mesmo lugar e a canoa ia para frente (CAMPOS, 1960, p. 169). Dependendo do tamanho da embarcação, iam quatro, cinco, às vezes, até seis Vareiros de cada lado da canoa que, com uma vara de aproximadamente seis metros de comprimento e sete quilos de peso, com uma das pontas apoiada em seu peito, já calejado do "exercício" diário, e a outra no fundo do rio, empurravam toneladas de mercadorias rio Grajaú abaixo, rumo a Vitória do Mearim, transportando peles de animais silvestres, couro, babaçu, algodão, malva. E rio Grajaú acima, rumo à cidade do mesmo nome, levando pólvora, querosene, tecidos, cutelaria, remédios, louças, enfim, todo tipo de produtos industrializados, e, principalmente o sal.

O sal foi uma das mais importantes mercadorias transportada pelos Vareiros do rio Grajaú. Por ser o sertão maranhense uma região notadamente voltada 
para a pecuária, por volta de 1947 o sertão detinha cerca de 10\% de todo o gado do Estado do Maranhão, estima-se em 135.000 o número de cabeças de gado no sertão. Daí a popular expressão sertaneja: "ou o dá aos gados, ou perde o ferro"3". O preço de uma saca de sal pesando $40 \mathrm{~kg}$ no litoral maranhense em 1910 era de $2 \$ 000$. As imensas dificuldades de transporte ao sertão fizeram seu preço atingir níveis estratroféricos, seu preço em Carolina alcançou $24 \$ 000$ e em Porto Franco $40 \$ 000$.

A jornada diária de trabalho do Vareiros ia até, aproximadamente, duas a três horas da tarde, quando paravam para comer um chiibét. Retomavam e trabalhavam aproximadamente até as sete horas da noite. Quando era noite de lua cheia, iam até mais ou menos nove horas. Jantavam geralmente o que haviam almoçado. O esforço desprendido para impulsionar, em média, seis mil quilos de mercadorias nas canoas era tanto, que alguns Vareiros adoeciam, adquiriam hérnias e malária, cuspiam sangue. Outros eram mordidos por cobras, todos invariavelmente feriam os pés e os peitos, muitos morreram espetados nas varas ou mesmo de malária. Os que morriam durante a viagem de trabalho eram enterrados nas margens do rio Grajaú.

$\mathrm{Na}$ paisagem de homens em movimento, no vai e vem de canoas, "caminhos eram abertos no leito do rio a enxada, enxadeco 5 e a pratos de alumínio." Tinha dia que não se andava cem metros "(CAMILO, 2006) 6 . Durante a faina diária, os Vareiros eram picados por um tipo de besouro chamado cabo verde e à noite por pernilongos, tal sofrimento só era suportável devido ao alto consumo diário de maconha: "Eu comprava 80 quilos de diamba7 para uma viagem de ida e volta". (MARTINS, 2005) ${ }^{8}$. Cada viagem durava entre trinta e quarenta e cinco dias. Tais agruras diárias eram acrescidas pelas feridas abertas nos pés em decorrência do intenso contato com a água. As feridas eram tratadas à noite com azeite de castanha de caju fervido. O Vareiro "passava um insope nas curuba e quando o dia raiava

\footnotetext{
${ }^{3}$ Citado por VIVEIROS, Jerônimo de. In: História do Comércio do Maranhão. 1896-1934 São Luís, 3. ed. Associação Comercial do Maranhão, 1962, p.200.

${ }^{4}$ Era um tipo de refeição que misturavam farinha de mandioca, com água do rio e um bom pedaço de carne.

${ }^{5}$ Instrumento de trabalho cujo tamanho é a metade de uma enxada.

${ }^{6}$ Depoimento prestado ao Autor por José Camilo, idade incerta, em 14/12/2006.

${ }^{7} \mathrm{Um}$ dos nomes da maconha na região. Os efeitos nocivos provocados pelo uso da Cannabis sativa .Cf. http://jovempan.uol.com.br/jpamnew/destaques/campanha/index.php?lock=321 acessado em 15/07/2007.

${ }^{8}$ Depoimento prestado ao Autor por Deodato Martins, 82 anos, na cidade de Grajaú - MA em 20/01/2007.
} 
começava tudo de novo"(CAMILO, 2006). As condições de dormir desses homens eram igualmente adversas: "dormiam na proa da canoa, ao relento, cobriam uma das orelhas com uma "coité" , em noites de chuva fina para evitar entrar água e insetos no ouvido. Só conseguiam pegar no sono graças a diamba."(RODRIGUES, 2007).

Quarenta e cinco dias após o início da viagem, nem todos regressavam às suas famílias. Alguns haviam sido enterrados nas margens do rio Grajaú e os que voltavam encontravam toda sorte de sofrimentos e humilhações, pelo fato de suas famílias estarem submetidas a um cotidiano de privações, não tendo acesso aos gêneros alimentícios que suprimissem suas necessidades diárias. A sobrevivência era conseguida praticamente da caridade pública. As mulheres "índias sobreviviam, vendendo lenha na cidade" (GUAJAJARA, 2007) ${ }^{10}$.

As condições de vida as quais estavam submetidos os Vareiros do rio Grajaú, no início do século XX, apontam para a problemática das permanências de um trabalho análogo à escravidão. A pobreza e a miséria de suas vidas tornaram-lhes igualmente cativos de um trabalho desumano e insalubre. Desse modo, retomar as experiências de vidas desses sujeitos por meio da memória possibilita uma reflexão sobre a importância desses trabalhadores para o desenvolvimento socioeconômico do centro sul maranhense comparando suas condições de trabalho à escravidão. Por meio da memória dos Vareiros sobreviventes, é possível entender um pouco a complexidade desses homens simples pelas jornadas de trabalho, pelos salários não recebidos ou ainda as muitas doenças que adquiriam impedindo-lhes de voltarem a trabalhar ficando entregues à própria sorte. "Era um cativeiro, vareiro; foi o bicho que mais sofreu no mundo" (ARRUDA, 2007).

\section{CONSIDERAÇOES FINAIS}

A "profissão" de Vareiro não mais existe. Acabou no início dos anos 60 do século passado com a chegada ao município de Grajaú das rodovias. Utilizando o conceito de memória coletiva de Walbwachs apud Seixas que "confere o atributo de atividade natural, espontânea, desinteressada e seletiva, que guarda do passado

\footnotetext{
${ }^{9}$ Espécie de uma pequena cabaça cortada ao meio.

${ }^{10}$ Depoimento prestado ao Autor por Virgulino Guajajara, (Índio), 86 anos, na aldeia Morro Branco, município de Grajaú - MA em 21/01/2007.
} 
apenas o que lhe possa ser útil para criar um elo entre o presente e o passado" (SEIXAS, 2004, p.40), como preservar a memória dessa atividade profissional, que tanto contribuiu para o desenvolvimento do sul do Maranhão e mesmo para a criação de um mercado regional com os estados vizinhos, se hoje ela não é 'útil' para a atual sociedade? Erguendo um monumento? Acreditamos que não. Não compreende o articulista citado no início desse trabalho que os Vareiros do rio Grajaú pertencem à história e não mais à memória. A própria solicitação do articulista da construção de um monumento é uma demonstração inequívoca de que a memória encontra-se prisioneira da história e como disse (NORA, 1993, p.7) "fala-se memória precisamente porque ela não existe mais".

\section{VAREIROS IN THE RIVER GRAJAÚ}

ABSTRACT: This study examines the history and memory of working conditions of the river vareiros Grajaú, located in the centre south Maranhão, at the beginning of the twentieth century, discussing how those activities performed by black men and Indians can be considered analogous to slavery to the authors E.P.Thompson and Frederick Cooper. It makes a reflection from the authors Jacy Alves de Seixas, Michael Pollak, Pierre Nora and Maurice Halbwachs about the question of memory.

KEY WORDS: Maranhão, River Navigation, Memory, Men Free, slavery.

\section{REFERÊNCIAS}

ALBERTI, Verena. Ouvir Contar Textos de História Oral. Rio de Janeiro: Editora FGV, 2004.

CABRAL, Maria do Socorro Coelho. Caminhos do Gado: conquista e ocupação do Sul do Maranhão. São Luís: Sioge, 1992.

CAMPOS, Humberto de. Memórias Inacabadas. São Paulo: Gráfica e Editora Brasileira Ltda. 1960.

CARVALHO, Carlota. O Sertão: subsídios para a história e a geografia do Brasil. Imperatriz: Ética, 2000. 
COOPER, Frederick. HOLT, C. Thomas, SCOTT, Rebecca J. Além da Escravidão. Investigação sobre raça, trabalho e cidadania em sociedades pós-emancipação. Tradução de Maria Beatriz de Medina. Rio de Janeiro: Civilização Brasileira, 2005.

DINO, Sálvio. Os Vareiros do Grajaú. Jornal O Estado do Maranhão. Caderno Alternativo. São Luís, 25 de junho de 2005, p.25.

HALBWACHS, Maurice. A Memória Coletiva. Tradução de Beatriz Sidou. São Paulo: Centauro Editora, 2006.

NORA, Pierre. Entre Memória e História. A problemática dos lugares. Tradução de Yara Aun Khoury. Projeto História, São Paulo, PUC, n. 10, p. 07-28, dez, 1993.

POLLACK Michael. Memória e Identidade Social. Estudos Históricos. Rio de Janeiro, CPDOC-FGV, v.5, n.10, p. 200-215, 1992.

SEIXAS, Jacy Alves de. Percursos de Memória em terras de história: Problemáticas Atuais. p. 37-58. In: BRESCIANI, Stella; NAXARA, Márcia. (Orgs). Memória E (Res)sentimento. Indagações sobre uma questão sensível. Campinas-SP, Editora da Unicamp, 2004.

THOMPSON, E. P. Costumes em Comum. Tradução Rosaura Eichemberg. São Paulo: Companhia das Letras, 1998.

VIVEIROS, Jerônimo de. História do Comércio do Maranhão 1896-1934. São Luís. 3. ed. Associação Comercial do Maranhão, 1962, p.200.

\section{ENTREVISTAS}

ARRUDA, Luiz Alves de.

CAMILO, José.

GUAJAJARA, Virgulino.

MARTINS, Deodato.

RODRIGUES, José Maria.

SILVA, Edvalso. 